\title{
ANALISIS PENERIMAAN DASHBOARD MONITORING PENDATAAN SENSUS PENDUDUK 2020 PROVINSI NUSA TENGGARA BARAT MENGGUNAKAN TECHNOLOGY ACCEPTANCE MODEL
}

\author{
Anang Zakaria \\ Badan Pusat Statistik Provinsi Nusa Tenggara Barat \\ Jln. Gunung Rinjani no. 2 - Dasan Agung Baru - Kota Mataram \\ anangz@bps.go.id
}

\begin{abstract}
Abstrak - Pendataan lapangan Sensus Penduduk 2020 (SP2020) telah selesai dilakukan pada bulan September. Kegiatan pendataan lanjutan adalah pelaksanaan SP2020 Long Form pada bulan Agustus-September 2021. Untuk keperluan pemantauan perkembangan pendataan maka BPS Provinsi NTB membuat sistem monitoring pelaporan pendataan petugas sensus. Dashboard Monitoring Pendataan SP2020 berbasis web digunakan sebagai media informasi perkembangan kegiatan lapangan yang dapat dimanfaatkan oleh pemantau, kepala satuan kerja, subject matter dan unit kerja pengolahan data di seluruh Satuan Kerja Organsiasi. Penelitian ini bertujuan untuk melihat penerimaan dashboard monitoring pendataan SP2020 September oleh pengguna. Hasil analisis penerimaan ini selanjutnya digunakan sebagai masukan untuk pengembangan Dashboard Monitoring Pendataan SP2020 Long Form. Analisis penerimaan Dashboard Monitoring Pendataan SP2020 menggunakan Technology Acceptance Model (TAM). Penghitungan analisis data menggunakan Partial Least Square-Structural Equation Model (PLS-SEM) dengan bantuan perangkat lunak SmartPLS versi 3. Hasil analisis data menyimpulkan bahwa seluruh hipotesis yang menghubungkan variabel laten dinyatakan diterima. Hasil penelitian memperlihatkan ada pengaruh Behavioral Intention (BI) terhadap Use Behavior (UB), ada pengaruh Perceived Usefulness (PU) dan Perceived Ease of Use (PEoU) terhadap Behavioral Intention (BI), ada pengaruh Output Quality (OQ) terhadap Perceived Usefulness (PU) serta ada pengaruh Computer Self Efficacy (CSE) terhadap Perceived Ease of Use (PEoU).
\end{abstract}

Kata Kunci : SP2020 Long Form, Technology Acceptance Model, Partial Least Square, Structural Equation Model, Output Quality, Computer Self Efficacy, Perceived Usefulness, Perceived Ease of Use, Behavioral Intention, Use Behavior.

\section{PENDAhUluan}

Ada 2 hal utama mengapa diperlukan monitoring suatu kegiatan. Pertama, monitoring dibutuhkan untuk memberikan informasi tentang sebab akibat suatu kebijakan harus dilakukan. Kedua, dengan adanya monitoring maka antisipasi bisa segera dirancang dan diimplementasikan jika terjadi hambatan atau kesalahan, sehingga dampak negatif yang lebih besar bisa dihilangkan atau dikurangi [1]. Dari penjelasan tersebut dapat disebutkan salah satu tujuan monitoring adalah untuk menemukan kesalahan sedini mungkin sehingga mengurangi risiko yang lebih besar yang bisa menghambat pelaksanaan kegiatan. Hal tersebut senada dengan konsep monitoring atau pemantauan dalam Peraturan Pemerintah nomor 39 Tahun 2006 tentang Tata Cara Pengendalian dan Evaluasi Pelaksanaan Rencana Pembangunan. Monitoring atau kegiatan pemantauan dimaksudkan untuk mengamati perkembangan pelaksanaan rencana pembangunan; mengidentifikasi serta mengantisipasi permasalahan yang timbul dan atau akan timbul untuk dapat diambil tindakan sedini mungkin [2].

Monitoring mempunyai empat fungsi, yaitu: ketaatan (compliance), pemeriksaan (auditing), laporan (accounting) dan penjelasan (explanation). Dalam Peraturan Pemerintah Nomor 39 Tahun 2006 tentang evaluasi dan pengendalian pelaksanaan rencana pembangunan, bahwa monitoring merupakan suatu kegiatan mengamati secara seksama suatu keadaan atau kondisi, termasuk juga perilaku atau kegiatan tertentu dengan tujuan agar semua data masukan atau informasi yang diperoleh dari hasil pengamatan tersebut dapat menjadi landasan dalam mengambil keputusan tindakan selanjutnya yang diperlukan [3]. Dalam melakukan kegiatan monitoring suatu kegiatan diperlukan alat atau media untuk melihat secara mudah dan cepat perkembangan dan kemajuan kegiatan yang diamati. Salah satu tool yang bisa digunakan dalam pemantauan tersebut adalah dashboard kegiatan.

Dashboard adalah alat visualisasi dalam business intelligence sebagai aplikasi yang berhubungan langsung dengan pengguna akhir [4]. Dasbor kinerja atau performance 
dashboard merupakan suatu sistem penyampaian informasi secara berlapis mulai dari jenis informasi itu sendiri, peringatan dan wawasan atau pandangan sebagaimana yang diinginkan oleh pengguna sehingga pengguna dapat melakukan pengukuran, pemantauan dan pengelolaan kinerja dengan efektif [5]. Sesungguhnya dashboard diniatkan untuk menggambarkan kinerja organisasi dan individu. Dashboard ditujukan secara khusus untuk presentasi metrik dan peringatan kinerja organisasi dan individu. Metrik adalah pengukuran aktivitas untuk mengevaluasi kinerja, sebagian besar dalam kerangka waktu, geografi, dan agregasi relatif. Dashboard adalah wajah dari bidang manajemen informasi yang baru muncul. Dashboard telah menjadi kendaraan eksekusi untuk beberapa inisiatif utama yang sedang diterapkan di antara organisasi di seluruh dunia [6].

Penelitian tentang monitoring salah satunya telah dilakukan oleh Nuryani dan Romdoni pada tahun 2020. Kedua peneliti membuat perancangan aplikasi monitoring kebersihan baik sarana maupun prasarana di lingkungan kampus Universitas Bina Bangsa Kota Serang. Selama ini pihak pimpinan maupun pengelola di bagian sarana prasarana mengalami kesulitan dalam memantau kondisi kebersihan di seluruh ruangan dan tempat terbuka secara real time. Berdasarkan alasan tersebut maka kedua peneliti merancang aplikasi untuk memantau kebersihan di kampus agar tercipta kualitas kebersihan kampus yang lebih baik sehingga dapat meningkatkan dan memperlancar proses belajar mengajar [7]. Pada dasarnya aplikasi monitoring banyak digunakan dengan memanfaatkan kemajuan teknologi informasi sehingga informasi pada kegiatan yang sedang diamati dapat diperoleh dengan lebih mudah dan cepat serta tepat [8].

Sophan dan Sriyani menguji pembuatan aplikasi untuk memonitor kegiatan Kuliah Kerja Nyata mahasiswa pada Universitas Trunojoyo Madura. Aplikasi monitoring kegiatan KKN tersebut mencakup presensi, keberadaan lokasi mahasiswa dan dosen serta input data penilaian yang dilakukan oleh dosen. Pengujian akhir menunjukkan bahwa $71,78 \%$ aplikasi efektif diterapkan di lapangan KKN [9]. Rahmawati et al membangun aplikasi monitoring pengawas sekolah pada Dinas Pendidikan Kota Malang. Pada awalnya proses evaluasi dan monitoring pada pengawasan sekolah Pendidikan Anak Usia Dini (PAUD) dikerjakan dengan cara manual. Semula pengawas sekolah menyerahkan hardcopy laporan pengawasan, dokumen Sasaran Kerja Pegawai (SKP) dan dokumen pendukung lainnya. Setelah itu seluruh data pada dokumen diinput ke lembar kerja atau spreadsheet secara manual guna diproses pada tahap selanjutnya. Berdasarkan nilai yang diperoleh dari pengujian usability diperoleh angka 80,62. Dengan nilai sebesar itu dapat disimpulkan bahwa antarmuka sistem adalah baik dan mudah dipakai oleh pengguna [10].

Nama et al telah merancang dan membangun sebuah dashboard berbasis web yang dapat memantau penggunaan liteBIG instant messenger. Dengan adanya web dashboard tersebut membantu petugas dalam memantau status layanan terkini termasuk penggunaan sumber daya dan user statistic [11]. Sementara itu Kunang dan Purnamasari mengembangkan dashboard pemantauan cuaca pada Automatic Weather Station (AWS) milik Pusat Sains dan Teknologi Atmosfer Lembaga Penerbangan dan Antariksa Nasional (PSTA LAPAN). Dengan keberadaan web dashboard monitoring tersebut maka informasi dapat disajikan tepat waktu, baik informasi dari AWS maupun carbon logger data kepada masyarakat luas [12].

Penelitian yang dilakukan oleh Hermanto dan Patmawati menyimpulkan bahwa computer self efficacy (CSE) berpengaruh terhadap konstruk PU dalam penggunaan aplikasi akuntansi oleh mahasiswa Sekolah Tinggi Ilmu Ekonomi Surabaya (STIESIA). Kedua peneliti tersebut menggunakan model Technology Acceptance Model-2 (TAM2) dalam penelitiannya [13]. Sementara itu penggunaan sistem pembelajaran jarak jauh melalui video conference dapat diterima oleh siswa [14]. Dari hasil penelitian tersebut, meskipun siswa belum memiliki Kemampuan Menggunakan Komputer (Computer Self Efficacy) dan belum memiliki Persepsi Kemudahan Penggunaan (Perceived Ease of Use), Persepsi Penggunaan (Perceived Usefulness), Sikap Untuk Menggunakan (Attitide Toward Using), dan Minat Menggunakan (Intention to Use) memiliki efek yang sangat tinggi terhadap Penggunaan Aktual (Actual Use) pada aplikasi konferensi video (video conference) kegiatan belajar dan mengajar jarak jauh. Dalam penelitian penggunaan Sistem Informasi Akademik (SIA) pada Perguruan Tinggi Bina Sarana Informatika (BSI) di Bandung, Wiguna menemukan bahwa secara parsial variabel Perceived Ease of Use (PEoU) memperlihatkan tidak adanya pengaruh positif yang nyata terhadap Behavioral Intention (BI). Hasil penilaian yang diberikan oleh dosen dan karyawan terhadap antarmuka SIA ternyata menyimpulkan tidak mendukung variabel niat pengguna sistem [15].

EWSKIA merupakan aplikasi yang digunakan oleh bidan yang berfungsi untuk mencatat atau merekam dan pemantauan kesehatan ibu hamil dan melahirkan. Dalam analisis penerimaan sistem informasi EWSKIA di Kabupaten Grobogan, Kabupeten Temanggung, dan Kota Salatiga sangat dipengaruhi oleh persepsi bidan terhadap kemudahan penggunaan atau PEoU dan kemanfaatan sistem atau PU. Dengan demikian sistem EWSKIA lebih mudah diterima oleh bidan jika mereka merasa yakin bahwa EWSKIA mudah digunakan serta dirasakan manfaatnya dalam membantu penyelesaian pekerjaan [16].

Badan Pusat Statistik (BPS) telah melaksanakan pendataan Sensus Penduduk 2020 (SP2020) pada bulan SeptemberOktober 2020 lalu. Kegiatan lapangan SP2020 melibatkan banyak petugas sensus yang harus bertugas meliputi seluruh Satuan Lingkungan Setempat atau SLS [17]. Pada saat pelaksanaan lapangan BPS pusat tidak menyediakan sistem informasi untuk pelaporan dan monitoring yang dilaksanakan oleh PS di lapangan. Sehubungan dengan itu BPS Provinsi Nusa Tenggara Barat (NTB) berinisiatif membangun suatu 
sistem informasi yang bisa memenuhi tujuan monitoring kegiatan lapangan berupa dashboard berbasis web.

Kegiatan SP2020 masih berlanjut pada tahun 2021 pada bulan Agustus yang disebut sebagai SP2020 Long Form. Sebagaimana dengan kegiatan lapangan SP2020 September maka diperlukan sistem pemantauan kegiatan pada kegiatan lapangan SP2020 Long Form. Tujuan penelitian adalah untuk mengetahui tingkat penerimaan Dashboard Monitoring Pendataan Lapangan SP2020. Informasi tersebut dianggap penting karena sistem serupa direncanakan akan digunakan kembali pada kegiatan pendataan SP2020 Long Form pada bulan Agustus 2021 jika BPS pusat tidak menyediakan sistem monitoring pendataan lapangan.

\section{Metodologi Penelitian}

Penelitian ini menggunakan pendekatan kuantitatif. Kerangka model TAM dalam penelitian ini diadopsi dari kerangka teoritis TAM3 dengan penyesuaian sesuai kondisi objek penelitian. Gambar 1 menunjukkan model penerimaan Dashboard Monitoring Pendataan SP2020 yang digunakan dalam penelitian ini.

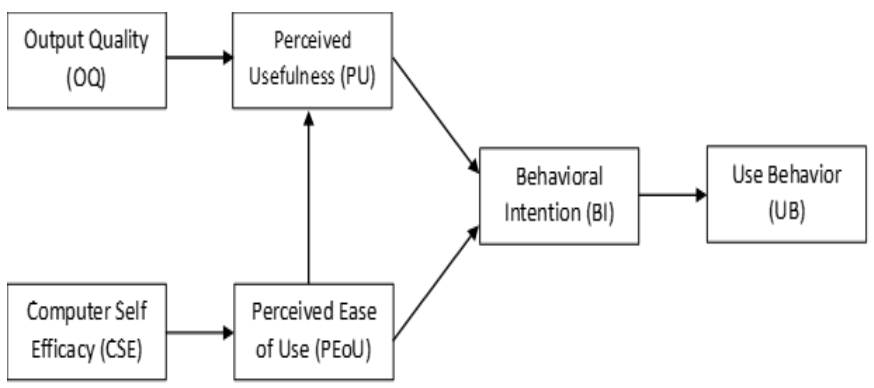

Gambar 1. Model Penerimaan Dashboard Monitoring Pendataan SP2020 (mengadopsi Venkatesh \& Bala, 2008)

Technology Acceptance Model (TAM) merupakan pengembangan dari Theory of Reasoned Action (TRA). TRA pertama kali dikenalkan oleh Ajzen dan Fishbein pada tahun 1980 dalam bukunya yang berjudul Understanding Attitudes and Predicting Social Behavior [18]. Kemudian pada tahun 1986 TRA dikembangkan menjadi TAM oleh Davis et al [19]. Sebagai pengembangan dari TRA pada kerangka TAM ditambahkan 2 konstruk utama ke dalam TRA yakni: Perceived Usefulness dan Perceived Ease of Use sebagai faktor penentu perilaku penerimaan komputer [20]. Pencetus TAM berkesimpulan bahwa penerimaan seseorang terhadap teknologi informasi ditentukan oleh 2 kontruk utama tersebut [18][21] mengembangkan TAM menjadi TAM2. Venkatesh dan Bala menggabungkan TAM2 dan model determinan persepsi kemudahan penggunaan [22] untuk mengembangkan model terintegrasi penerimaan teknologi menjadi TAM3 [23].

Berikut penjelasan masing-masing konstruk yang digunakan dalam penelitian ini:

- Output Quality (OQ) adalah sejauh mana pengguna percaya bahwa sistem mampu bekerja sesuai tugasnya
[21]. Pertimbangan pengguna terhadap kemampuan sistem tersebut disebut sebagai Perceived Output Quality [24]. Selain itu Output Quality memiliki pengaruh interaktif yang positif terhadap Perceived Usefulness [21] [24]. Computer Self Efficacy (CSE) adalah seberapa tingkat keyakinan pengguna terhadap kemampuan menggunakan komputer secara kompeten. Self-efficacy secara umum dimaksudkan sebagai tingkat keyakinan bahwa seseorang memiliki kemampuan untuk melakukan perilaku tertentu yang merupakan konstruksi penting dalam psikologi sosial [25][26].

- Perceived Usefulness (PU) adalah sejauh mana seseorang percaya dengan menggunakan sistem akan meningkatkan kinerjanya [18][26][27]. Perceived Easy of Use (PEoU) adalah sejauh mana seseorang percaya bahwa dengan menggunakan sistem akan terbebas dari upaya fisik dan mental [18][26].

- Behavioral Intention (BI) adalah sejauh mana seseorang telah meurumuskan untuk melakukan atau tidak melakukan suatu perilaku yang telah ditentukan [28][29]. Selama bertahun-tahun, BI telah menjadi penentu penggunaan teknologi informasi yang paling umum ke dalam adopsi teknologi informasi tingkat individu dan model serta dalam studi penggunaan [30]. Menurut TAM bahwa niat perilaku dalam penggunaan teknologi merupakan fungsi dari Perceived Usefulness dan Perceived Easy of Use [23]. Secara lebih spesifik bahwa niat seperti hal itu disebut sebagai niat implementasi (niat untuk menggunakan sistem) dalam pencapaian tujuan yakni meningkatkan kinerja [27].

- Use Behavior (UB) didefinisikan sebagai sebarapa sering frekuensi seseorang menggunakan suatu sistem dalam kurun waktu tertentu [26][23]. penggunaannya. Bentuk pengukuran penggunaan sesungguhnya atau senyatanya (actual use) adalah frekuensi dan durasi waktu penggunaan terhadap teknologi informasi. Penggunaan teknologi sesungguhnya (actual technology use), diukur dengan jumlah waktu yang digunakan untuk berinteraksi dengan teknologi dan frekuensi penggunaan [31].

Data dalam penelitian ini menggunakan data primer yang dikumpulkan langsung dari pengguna Dashboard Monitoring Pendataan SP2020. Pengguna web dashboard tersebut tersebar di BPS Provinsi NTB dan seluruh BPS kabupaten/kota yang terlibat langsung dalam kegiatan monitoring kegiatan SP2020. Pengumpulan data dilakukan dengan menggunakan kuesioner yang berisi daftar pernyataan sesuai indikator dalam konstruk model yang digunakan yaitu 20 indikator. Sedangkan setiap pernyataan pada indikator menggunakan 4 skala Likert: 1. Sangat Tidak Setuju (STS), 2. Tidak Setuju (TS), 3. Setuju (S), 4. Sangat Setuju (SS). 


\section{A. Pengumpulan Data}

Penelitian ini menggunakan data primer melalui pengumpulan data ke pengguna Dashboard Monitoring Pendataan SP2020 yang tersebar di seluruh satker BPS se NTB. Jumlah kuesioner yang masuk sebanyak 63 responden yang seluruhnya menjawab dengan lengkap 20 pertanyaan. Daftar variabel dan indikator dalam penelitian ini bersumber dari [23] dan [13] secara rinci dapat dilihat pada lampiran.

\section{B. Pengolahan Data}

Selanjutnya data sebanyak 63 responden diolah dengan menggunakan software SmartPLS 3 menggunakan teknik path analysis. Untuk melakukan analisis data hasil pengumpulan data primer dalam penelitian ini menggunakan Partial Least Square-Structural Equation Model (PLS-SEM). PLS-SEM merupakan metode analisis statistik yang cukup andal. Keunggulan PLS-SEM salah satunya dapat diimplemtasikan pada semua skala data pengukuran termasuk skala ordinal. Selain itu dalam PLS-SEM tidak memerlukan banyak asumsi serta jumlah kasus yang diolah tidak harus besar [32][33][34]. Penelitian menggunakan PLS atau kuadrat terkecil parsial merupakan bagian dari analisis jalur atau path analysis. Banyak peneliti menggunakan PLS sebagai alat analisis data karena kemampuannya yang baik dalam menelaah model yang melibatkan banyak variabel konstruk dengan berbagai skala pengukuran. Dalam pengolahan data dengan jumlah kasus kecil sekitar 20-50 sampel maka PLS dianggap cocok untuk diterapkan [35].

\section{Hipotesis}

Berdasarkan model penelitian yang terdapat pada Gambar 1 , berikut adalah hipotesis yang akan diuji menggunakan metode PLS-SEM:

H1: Output Quality (OQ) berpengaruh terhadap Perceived Usefulness (PU)

H2: Self Computer Efficacy (CSE) berpengaruh terhadap Perceived Ease of Use (PeoU)

H3: Perceived Ease of Use (PeoU) berpengaruh terhadap Perceived Usefulness (PU)

H4: Perceived Usefulness (PU) berpengaruh terhadap Behavioral Intention (BI)

H5: Perceived Ease of Use (PeoU) berpengaruh terhadap Behavioral Intention (BI)

H6: Behavioral Intention (BI) berpengaruh terhadap Use Behavior (UB)

\section{Tahapan Analisis Data}

Sebelum melakukan analisis data perlu dirancang kerangka kerja analisis data. Dalam kerangka tersebut dimulai dari perancangan model hingga pengujian hipotesis.

Gambar 2 menunjukkan alur kerangka kerja analisis data menggunakan PLS-SEM. Inti dari analisis data dimulai pada alur ke 3 dan 4 setelah dilakukan penghitungan di perangkat lunak SmartPLS dengan menggunakan data hasil survei pengguna Dashboard Monitoring Pendataan SP2020.

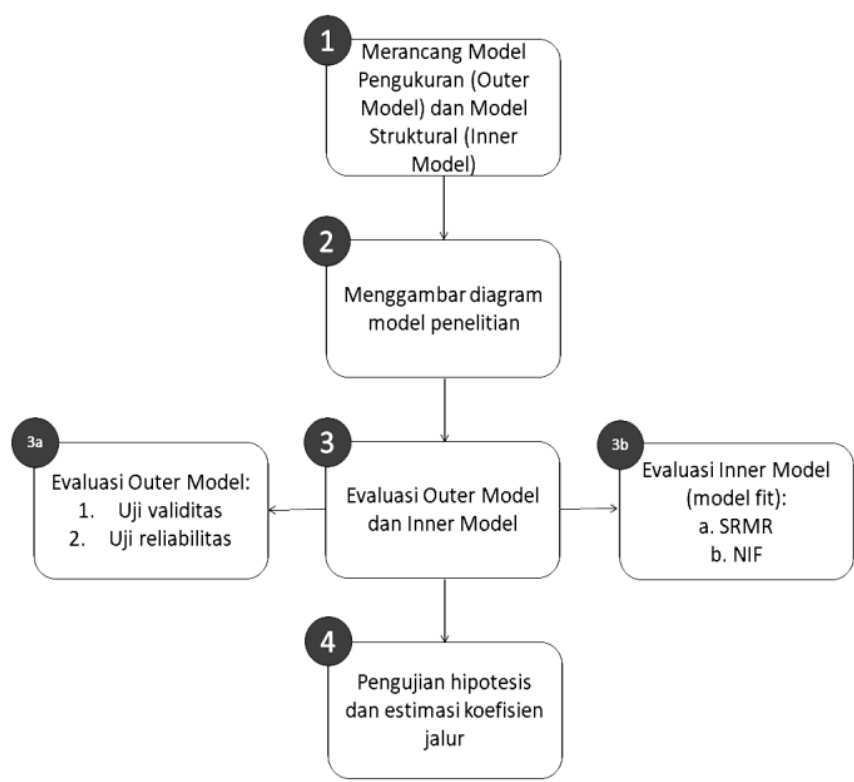

Gambar 2. Kerangka Kerja Analisis Data

\section{HASIL DAN PEMBAHASAN}

Dashboard monitoring dibuat dengan prinsip mudah, sederhana dan informatif. Prinsip mudah dalam pengertian cepat dalam pembuatan karena keterbatasan waktu tetapi mudah digunakan. Dashboard monitoring dibuat sederhana tanpa banyak tampilan gambar dan hanya tampilan grafik setengah lingkaran untuk memudahkan dalam melihat gambaran progres pendataan lapangan SP2020. Web dashboard monitoring dibuat untuk setiap satuan kerja (satker) mulai provinsi hingga 10 kabupaten/kota atau sebanyak 11 alamat web. Pembuatan 11 web dashboard dimaksudkan untuk meringankan akses dibandingkan seluruh satker berada dalam satu web dashboard. Adapun alamat web Dashboard Monitoring Pendataan Lapangan SP2020 adalah https://monsp20sXXXX.glideapp.io (XXXX=kode wilayah).

Prinsip informatif dalam dashboard monitoring SP2020 ditunjukkan dengan beberapa data yang berkaitan dengan jumlah penduduk. Informasi yang ada di dashboard monitoring selain hasil laporan yang dikirim lewat Telegram seperti jumlah penduduk dan jumlah keluarga juga ditampilkan sex ratio, jumlah penduduk hasil Sensus Penduduk 2010 (SP2010), jumlah penduduk hasil proyeksi Survei Penduduk Antar Sensus 2015 (Supas 2015) dan persentase SLS yang telah diselesaikan terhadap target. Angka-angka tersebut ditampilkan dengan harapan dapat digunakan sebagai indikator peringatan dini terhadap progres atau pencapaian kegiatan pendataan lapangan SP2020. Gambar 3 adalah contoh tangkapan layar web Dashboard Monitoring Pendataan SP2020. 


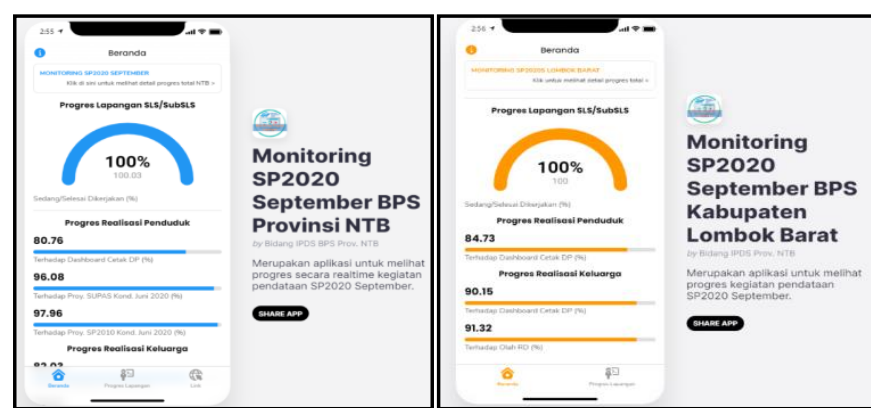

Gambar 3. Contoh Tampilan Dashboard Monitoring Pendataan SP2020

\section{A. Uji Validitas dan Uji Reliabilitas}

Secara lengkap kriteria untuk melakukan pengujian validitas dan reliabilitas dengan menggunakan penghitungan dari perangkat lunak SmartPLS dapat dilihat pada Tabel 1 berikut

TABEL I.

KRITERIA PENGUJIAN VALIDITAS DAN RELIABILITAS

\begin{tabular}{|c|c|c|}
\hline $\begin{array}{c}\text { Jenis } \\
\text { Pengujian }\end{array}$ & Pengukuran & Kriteria \\
\hline Uji validitas & Convergent validity & $\begin{array}{l}\text { Indikator valid jika outer loading } \\
\geq 0,7\end{array}$ \\
\hline \multirow{3}{*}{ Uji reliabilitas } & AVE & $\begin{array}{l}\text { Variabel laten valid jika nilai } \\
A V E \geq 0,5\end{array}$ \\
\hline & Composite reliability & $\begin{array}{l}\text { Variabel laten reliabel jika nilai } \\
\text { composite reliability } \geq 0,7\end{array}$ \\
\hline & Cronbach's Alpha & $\begin{array}{l}\text { Variabel laten reliabel jika } \\
\text { Cronbach's Alpha } \geq 0,7\end{array}$ \\
\hline
\end{tabular}

Batasan umum yang digunakan dalam convergent validity untuk menentukan apakah suatu indikator valid adalah jika nilai outer loadings $\geqslant 0,7[33]$.

TABEL II.

NILAI OUTER LOADINGS INDIKATOR

\begin{tabular}{|c|c|c|c|c|c|c|c|}
\hline & $\begin{array}{c}\text { Output } \\
\text { Quality } \\
\text { (OQ) }\end{array}$ & $\begin{array}{c}\text { Computer } \\
\text { Self } \\
\text { Efficacy } \\
\text { (CSE) }\end{array}$ & $\begin{array}{c}\text { Perceived } \\
\text { Usefulness } \\
\text { (PU) }\end{array}$ & $\begin{array}{c}\text { Perceived } \\
\text { Ease of } \\
\text { Use } \\
\text { (PEoU) } \\
\end{array}$ & $\begin{array}{l}\text { Behavioral } \\
\text { Intention } \\
\text { (BI) }\end{array}$ & $\begin{array}{c}\text { Use } \\
\text { Behavior } \\
\text { (UB) }\end{array}$ & Keputusan \\
\hline$\overline{\mathrm{OQ} 1}$ & 0,921 & & & & & & Valid \\
\hline OQ2 & 0,864 & & & & & & Valid \\
\hline OQ3 & 0,865 & & & & & & Valid \\
\hline CSE1 & & 0,854 & & & & & Valid \\
\hline CSE2 & & 0,828 & & & & & Valid \\
\hline CSE3 & & 0,716 & & & & & Valid \\
\hline PU1 & & & 0,909 & & & & Valid \\
\hline PU2 & & & 0,934 & & & & Valid \\
\hline PU3 & & & 0,899 & & & & Valid \\
\hline PU4 & & & 0,884 & & & & Valid \\
\hline PeoUl & & & & 0,898 & & & Valid \\
\hline PeoU2 & & & & 0,927 & & & Valid \\
\hline PeoU3 & & & & 0,892 & & & Valid \\
\hline PeoU4 & & & & 0,888 & & & Valid \\
\hline BI1 & & & & & 0,933 & & Valid \\
\hline BI2 & & & & & 0,966 & & Valid \\
\hline BI3 & & & & & 0,843 & & Valid \\
\hline UB1 & & & & & & 0,923 & Valid \\
\hline UB2 & & & & & & 0,864 & Valid \\
\hline UB3 & & & & & & 0,880 & Valid \\
\hline
\end{tabular}

Dari Tabel 2 terlihat seluruh indikator berstatus valid terlihat dari nilai outer loadings lebih dari 0,70 artinya bahwa seluruh indikator layak digunakan dalam model pengukuran. Keputusan tersebut memberikan petunjuk bahwa proses berikutnya pengujian reliabilitas pada variabel laten. Hasil pengujian reliabilitas dan validitas pada variabel laten dapat dilihat pada Tabel 3 .

Berdasarkan Tabel 3 terlihat seluruh variabel laten berstatus valid yang ditunjukkan oleh nilai AVE seluruhnya lebih besar dari 0,70. Sedangkan reliabilitas variabel laten dapat dilihat dari nilai Cronbach's Alpha atau Composite Reliability. Dari Tabel 3 nilai Cronbach's Alpha atau Composite Reliability seluruhnya lebih besar dari 0,70 yang bermakna bahwa seluruh variabel laten bersifat reliabel.

TABEL III

RELIABILITAS DAN VALIDITAS VARIABEL LATEN

\begin{tabular}{lccr}
\hline \multicolumn{1}{c}{ Variabel Laten } & $\begin{array}{c}\text { Cronbach's }^{\text {Alpha }}{ }^{*} \\
\text { Output Quality (OQ) }\end{array}$ & $\begin{array}{c}\text { Composite } \\
\text { Reliability }\end{array}$ & $\begin{array}{c}\text { Average } \\
\text { Variance } \\
\text { Extracted } \\
\text { (AVE) }\end{array}$ \\
\hline Computer Self Efficacy (CSE) & 0,729 & 0,843 & 0,781 \\
Perceived Usefulness (PU) & 0,928 & 0,949 & 0,822 \\
Perceived Ease of Use (PEoU) & 0,899 & 0,930 & 0,768 \\
Behavioral Intention (BI) & 0,903 & 0,939 & 0,838 \\
Use Behavior (UB) & 0,868 & 0,919 & 0,791
\end{tabular}

$*)=$ Reliabel $(\geq 0,70), * *)=$ Valid $(\geq 0,50)$

Berdasarkan evaluasi terhadap hasil pengujian validitas dan reliabilitas dapat disimpulkan bahwa model pengukuran (outer model) yang terdiri atas indikator dan variabel laten layak untuk dilakukan proses berikutnya yaitu pengukuran model fit dan pengujian hipotesis untuk melihat validitas model struktural (inner model).

TABEL IV

PENGUKURAN MODEL FIT

\begin{tabular}{lcl}
\hline & Saturated Model & Kriteria \\
\hline SRMR & 0,067 & SRMR $<0,10$ model dianggap cocok \\
NFI & 0,753 & $\begin{array}{l}\text { NFI bernilai antara 0 dan 1, jika } \\
\text { mendekati 1 berarti model semakin baik }\end{array}$ \\
\hline
\end{tabular}

Sumber: [36]

Tabel 4 memperlihatkan hasil penghitungan PLS Algorithm pada perangkat lunak SmartPLS. Ukuran yang digunakan untuk melakukan evaluasi model fit adalah SRMR (Standardized Root Mean Square Residual) dan NFI (Normal Fit Index). Dengan menggunakan kriteria nilai SRMR $<0,10$ maka model dikatakan cocok, sedangkan jika nilai NFI 
mendekati 1 berarti model semakin baik. Berdasarkan Tabel 4 dengan nilai SRMR sebesar 0,067 maka model dikatakan cocok, sedangkan nilai NFI sebesar 0,753 yang menunjukkan model ke arah semakin baik. Kesimpulan dari evaluasi kedua ukuran tersebut adalah model struktural dianggap cocok atau fit dan semakin baik.

TABEL V.

KOEFISIEN DETERMINAN VARIABEL LATEN ENDOGEN

\begin{tabular}{lcc}
\hline Variabel Laten Endogen & $R$ Square & $\begin{array}{c}\text { R Square } \\
\text { Adjusted }\end{array}$ \\
\hline Perceived Usefulness (PU) & 0.674 & 0.663 \\
Perceived Ease of Use (PEoU) & 0.406 & 0.396 \\
Behavioral Intention (BI) & 0.698 & 0.688 \\
Use Behavior (UB) & 0.228 & 0.216 \\
\hline
\end{tabular}

Nilai koefisien determinan atau R Square (R2) variabel laten dapat dilihat pada Tabel 5 nilai R Square menunjukkan besaran koefisien determinasi pada variabel endogen. Nilai $\mathrm{R}$ Square sebesar lebih dari 0,7 dikatakan kuat; 0,67 substansial; 0,33 moderat dan 0,19 dikategorikan lemah [33]. Variabel UB (R2=0,228) yang merupakan dependent variable hanya bisa dijelaskan variasinya oleh variabel PU dan PEoU melalui variabel BI sebesar 22,8\%, dengan kata lain ada sebesar $77,2 \%$ variasi ditentukan oleh faktor lain. Oleh karena nilai $\mathrm{R}$ Square variabel UB sebesar $22,8 \%$ maka bisa dikelompokkan koefisien determinasinya lemah.

Adapun variasi variabel BI dapat dijelaskan oleh variabel PU dan PEoU sebesar 69,8\% yang berarti ada 30,2\% variasi yang dijelaskan oleh faktor lain. Nilai R Square sebesar $69,8 \%$ menunjukkan bahwa koefisien determinasinya substansial.

Setelah dilakukan pengujian validitas dan reliabilitas serta mengamati model fit yang diperoleh dari penghitungan PLS Algorithm yang menghasilkan keputusan valid, reliabel dan model cocok atau baik maka tahap berikutnya adalah pengujian hipotesis pada model struktural. Untuk mendapatkan nilai statistik pada uji hipotesis maka pada perangkat lunak SmartPLS menyediakan metode bootstrapping. Pada penghitungan bootsrapping dengan menggunakan nilai default 500 subsampel dan 300 iterasi maksimum diperoleh nilai statistik sebagaimana ditampilkan pada Tabel 6.

\section{B. Uji Hipotesis}

Pada Tabel 6 seluruh hipotesis H1 sampai dengan H6 dinyatakan diterima dengan taraf nyata $\alpha=5 \%$. Hal tersebut dapat dilihat dari nilai $\mathrm{p}$ Value yang seluruhnya lebih kecil dari taraf nyata 5\% dengan kata lain ada pengaruh antara satu konstruk terhadap konstruk yang lain. Cara lain untuk memutuskan pengujian hipotesis adalah dengan membanding nilai t hitung atau $\mathrm{t}$ Statistic (to) dengan nilai t table (t $\alpha$ ). Jika to $<$ t $\alpha$ maka hipotesis ditolak dengan taraf nyata $\alpha$. Nilai $t$ table dengan $\alpha=5 \%$ adalah 1,988 (t $\alpha$ ) sedangkan nilai to dapat dilihat pada Tabel pada kolom t Statistic. Pada tabel tersebut terlihat pada seluruh variabel laten nilai to $>$ t $\alpha$ yang memberikan kesimpulan seluruh hipotesis diterima pada taraf nyata 5\%. Arah hubungan (positif atau negatif) dapat dilihat dari tanda pada angka Original Sample $(\mathrm{O})$.

TABEL VI.

PENGUJIAN HIPOTESIS HUBUNGAN ANTAR VARIABEL LATEN

\begin{tabular}{|c|c|c|c|c|c|}
\hline Hipotesis & Hubungan & $\begin{array}{l}\text { Original } \\
\text { Sample } \\
(O) \\
\end{array}$ & $\begin{array}{c}t \\
\text { Statistics }\end{array}$ & $\begin{array}{c}p \\
\text { Values }\end{array}$ & $\begin{array}{l}\text { Keputusan } \\
\left.\text { Hipotesis }^{*}\right)\end{array}$ \\
\hline H1 & $\begin{array}{l}\text { Output } \\
\text { Quality (OQ) } \\
->\text { Perceived } \\
\text { Usefulness }\end{array}$ & 0,553 & 4,052 & 0,000 & Terima \\
\hline $\mathrm{H} 2$ & $\begin{array}{l}\text { Computer } \\
\text { Self Efficacy } \\
\text { (CSE) -> } \\
\text { Perceived } \\
\text { Ease of Use } \\
\text { (PEoU) }\end{array}$ & 0,637 & 9,189 & 0,000 & Terima \\
\hline H3 & $\begin{array}{l}\text { Perceived } \\
\text { Ease of Use } \\
\text { (PEoU) -> } \\
\text { Perceived } \\
\text { Usefulness } \\
\text { (PU) }\end{array}$ & 0,319 & 2,296 & 0,022 & Terima \\
\hline $\mathrm{H} 4$ & $\begin{array}{l}\text { Perceived } \\
\text { Usefulness } \\
\text { (PU) -> } \\
\text { Behavioral } \\
\text { Intention (BI) }\end{array}$ & 0,523 & 3,930 & 0,000 & Terima \\
\hline H5 & $\begin{array}{l}\text { Perceived } \\
\text { Ease of Use } \\
\text { (PEoU) -> } \\
\text { Behavioral } \\
\text { Intention (BI) }\end{array}$ & 0,372 & 2,968 & 0,003 & Terima \\
\hline H6 & $\begin{array}{l}\text { Behavioral } \\
\text { Intention (BI) } \\
->\text { Use } \\
\text { Behavior }\end{array}$ & 0,478 & 4,873 & 0,000 & Terima \\
\hline
\end{tabular}

Pada Tabel 6 terlihat arah hubungan seluruh hipotesis memiliki arah postif. Pada hipotesis H1 dapat disimpulkan bahwa ada konstruk Output Quality (OQ) berpengaruh terhadap konstruk Perceived Usefulness (PU) dengan arah positif. Arah pengaruh positif memberikan arti bahwa pada H1 jika kenaikan satuan pada variabel OQ maka PU juga akan naik. Berdasarkan angka Original Sample pada Tabel 6 jika OQ naik satu satuan maka PU akan naik 0,553 satuan dengan asumsi tidak ada pengaruh dari variabel yang lain. Kesimpulan serupa dengan pernyataan tersebut berlaku untuk hipotesis H2 sampai dengan H6. Berikut penjelasan setiap hipotesis.

H1: Output Quality (OQ) berpengaruh terhadap Perceived Usefulness (PU)

Hasil pengujian menunjukkan bahwa OQ berpengaruh dengan arah positif terhadap PU. Hal tersebut terlihat dari 
nilai $\mathrm{p}$ Value $(0,000)$ yang lebih kecil dari taraf nyata $\alpha(0,05)$ dengan nilai koefisien jalur sebesar 0,553. Keputusan hasil pengujian $\mathrm{H} 1$ ini sesuai dengan kesimpulan Arsyika et al yang meneliti penggunaan layanan cloud storage di Dinas Perpustakaan dan Arsip Kota Pekanbaru [37].

H2: Computer Self Efficacy (CSE) berpengaruh terhadap Perceived Ease of Use (PEoU)

Dengan nilai p Value sebesar 0,000 dan Original Sample (O) sebesar 0,637 sebagai koefisien jalur maka hipotesis H2 diterima yang berarti ada pengaruh variabel CSE terhadap PEoU dengan arah positif. Hasil ini mendukung penelitian Wang (2003) yang menganalisis penggunaan sistem pengisian pajak secara elektronik di Taiwan. Kemampuan diri dalam menggunakan sangat berpengaruh pada persepsi bahwa suatu sistem mudah digunakan atau tidak memerlukan upaya mental dan fisik [38][13]. Secara khusus dalam penelitian Al Azawei et al menyebut bahwa variabel Computer Self Efficacy sesuai subjek penelitiannya dinamakan blended e-learning system self-efficacy (BELSSE). Hasil penelitian Al Azawei et al dengan menggunakan PLS-SEM menyimpulkan bahwa ada pengaruh positif variabel BELSSE terhadap PEoU pada kajian pengaruh gaya pembelajaran pada e-learning system [39].

H3: Perceived Ease of Use (PEoU) berpengaruh terhadap Perceived Usefulness (PU)

Dari Tabel 6 terlihat bahwa pada hipotesis H3 memiliki nilai $\mathrm{p}$ Value sebesar 0,022 atau 2,2\% yang juga lebih kecil dari taraf 5\%. Dengan demikian hipotesis H3 diterima dengan arah pengaruh antara variabel PeoU terhadap PU positif (nilai $\mathrm{O}=0,319)$. Hasil serupa bisa ditemukan pada penelitian [38][40][39][41][37].
H4: Perceived Usefulness

Behavioral Intention (BI), dan

H5: Perceived Ease of Use (PEoU) berpengaruh terhadap Behavioral Intention (BI)

Hipotesis $\mathrm{H} 4$ diterima yang ditunjukkan oleh nilai $\mathrm{p}$ Value sebesar 0,000 yang berarti sangat signifikan pada taraf $\alpha=5 \%$ dengan arah positif $(\mathrm{O}=0,532)$.

Serupa dengan kesimpulan pada H4, pada H5 variabel PEoU berpengaruh positif terhadap variabel BI yang ditunjukkan oleh nilai p Value sebesar 0,003 dan koefisien jalur sebear 0,372. Pengaruh positif variabel PU dan variabel PEoU terhadap niat perilaku BI juga ditemukan pada penelitian lain seperti [38][42][41][37].

H6: Behavioral Intention (BI) berpengaruh terhadap Use Behavior (UB)

Bedasarkan Tabel 6 hipotesis H6 dapat diterima secara signifikan dengan $\mathrm{p}$ Value $=0,000$ dan dengan arah positif $(\mathrm{O}=0,478)$. Dengan demikian ada pengaruh positif variabel BI terhadap UB. Pada beberapa penelitian variabel Use Behavior disebut juga dengan Actual Use atau Actual Technology Use atau Actual System Use. Hasil penelitian yang serupa dengan kesimpulan H6 dapat ditemukan pada penelitian [13][37][41][43].

Gambar 4 merupakan model kerangka penelitian yang sudah dilengkapi dengan informasi seperti: nilai R Square (pada lingkaran variabel laten), nilai koefisien jalur (pada panah antar variabel laten) dan nilai t Statistic (pada panah antara indikator dan viariabel laten).

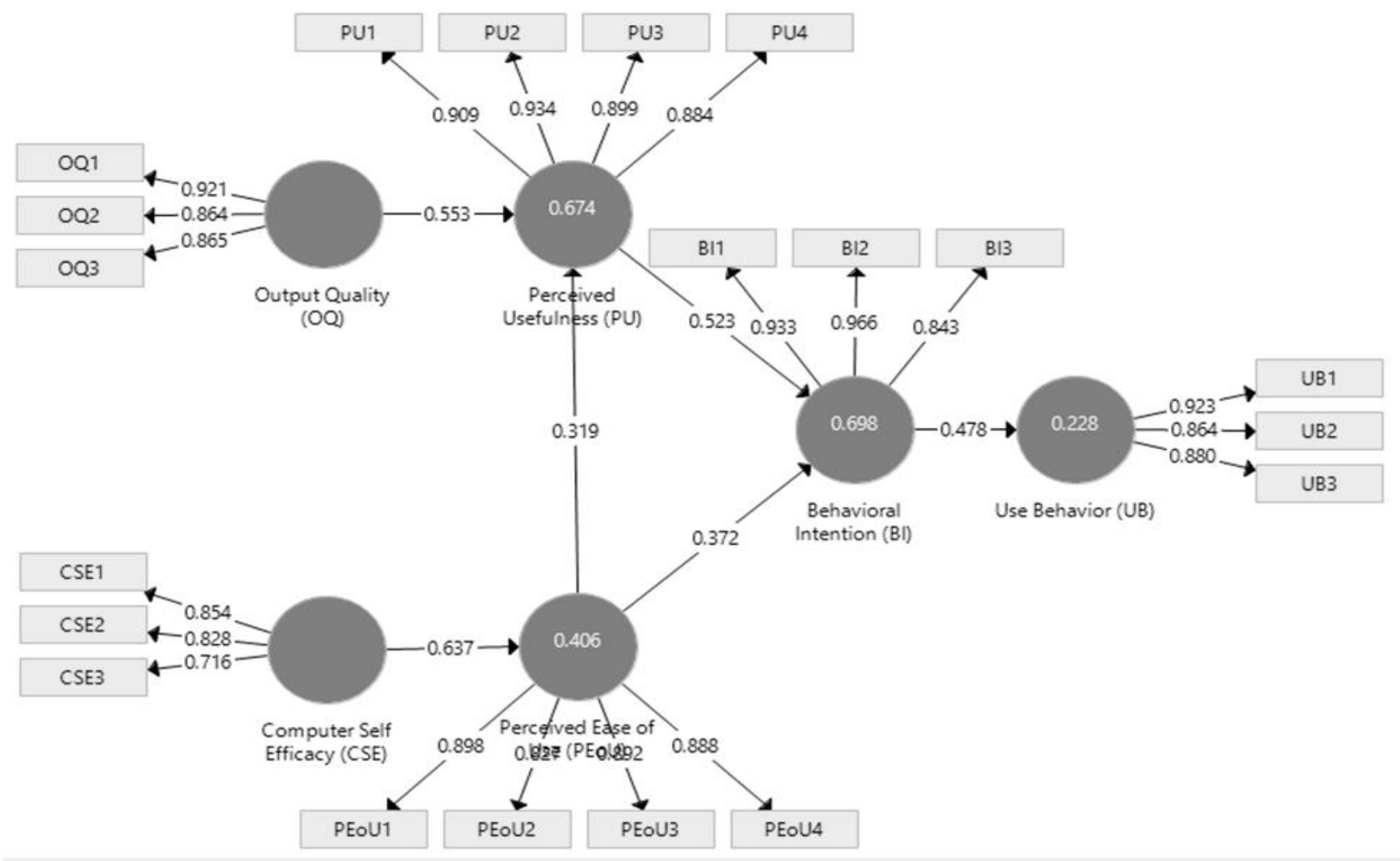

Gambar 4. Hasil PLS Algorithm dan Bootstrapping Model Penelitian 


\section{KESIMPULAN}

Berdasarkan hasil dan pembahasan analisis data di atas hipotesis yang diajukan seluruhnya diterima. Variabel Output Quality berpengaruh positif terhadap Percieved Usefulness, variabel Computer Self Efficacy berpengaruh positif terhadap Percieved Ease of Use, variable Percieved Ease of Use berpengaruh positif terhadap Percieved Usefulness, variabel Percieved Usefulness dan Percieved Ease of Use berpengaruh positif terhadap Behavioral Intention, dan variabel Behavioral Intention berpengaruh positif terhadap Use Behavior.

Koefisien determinan atau $\mathrm{R}$ Square model struktural sebesar 0,228 yang berarti bahwa variasi pada variabel dependen Use Behavior hanya bisa dijelaskan sebesar 22,8\% oleh Perceived Usefulness dan Perceived Ease of Use melalui variabel Behavioral Intention. Sedangkan sisanya yaitu sebesar 77,2\% variasi pada variabel Use Behavior dijelaskan oleh faktor lain di luar model.

Dari fakta di atas dapat disimpulkan bahwa Dashboard Monitoring Pendataan SP2020 bisa diterima oleh pengguna baik dengan alasan manfaat penggunaan maupun kemudahan dalam penggunaan. Keputusan penerimaan sistem tersebut juga timbul karena alasan kualitas output (Output Quality) yang baik sesuai kemampuan mandiri pengguna dalam hal kekomputeran (Computer Self Efficacy) yang memadai. Kondisi tersebut memberikan kesimpulan bahwa Dashboard Monitoring Pendataan SP2020 dipertimbangkan untuk digunakan kembali pada kegiatan pendataan SP2020 Long Form.

\section{UCAPAN TERIMA KASIH}

Pada akhirnya penulis selayaknya mengucapkan terima kasih dan penghargaan setinggi-tingginya kepada pihak-pihak yang turut berkontribusi dalam penelitian ini, yaitu:

1. Kepala Pusdiklat Badan Pusat Statistik dan jajarannya.

2. Dr. Novianto Budi Kurniawan (Fungsional Pranata Komputer Ahli Madya di Badan Pusat Statistik) selaku coach.

3. Teman-teman sejawat di Badan Pusat Statistik Provinsi Nusa Tenggara Barat.

Semoga Allah SWT membalas kebaikan bapak/ibu semua.

\section{REFERENSI}

[1] Setkab, "Pengertian Monitoring dan Evaluasi Kebijakan Pemerintah," 2015. https://setkab.go.id/pengertianmonitoring-dan-evaluasi-kebijakan-pemerintah (accessed Apr. 17, 2021).

[2] Peraturan Pemerintah Nomor 39, Tata Cara Pengendalian dan Evaluasi Pelaksanaan Rencana Pembangunan. MENTERI HUKUM DAN HAK ASASI MANUSIA, 2006.

[3] William N. Dunn, "William-N.-Dunn-PengantarAnalisis-Kebijakan-Pulblik-Gadjah-Mada-UniversityPress-2003_compressed-1.pdf.” p. 710, 2003.

[4] F. M. Putra and R. Sari, "Aplikasi Business Intelligence Dashboard sebagai Alat Monitoring dan Bahan
Pengambilan Keputusan Sales and Account Receivable,' MULTINETICS, vol. 2, no. 1, pp. 35-42, 2016. pp.35-42.

[5] W. W. Eckerson and J. Wiley, Performance Dashboards: Measuring, Monitoring and Managing Your Business, 2nd ed. Hoboken, New Jersey: John Wiley \& Sons, Inc., 2012.

[6] S. Malik, Enterprise Dashboard: Design and Best Practices for IT, vol. 53, no. 9. Hoboken, New Jersey: John Wiley \& Sons, Inc., 2005.

[7] E. Nuryani and M. Y. Romdoni, "Aplikasi Monitoring Kebersihan Sarana dan Prasarana Kampus Berbasis Web Menggunakan Teknik Responsif pada Android," vol. 7, no. 2, pp. 89-96, 2020.

[8] S. Sutarti and A. Alfiyansyah, "Analisis dan Implementasi Sistem Monitoring Koneksi Internet Menggunakan The Dude di STIKOM Al Khairiyah," JSiI (Jurnal Sist. Informasi), vol. 4, pp. 39-45, 2017.

[9] M. K. Sophan and Sriyani, "Monitoring kegiatan kuliah kerja nyata menggunakan fitur location based service," $J$. Sist. Inf. dan Ilmu Komput. Prima (JUSIKOM PRIMA), vol. 1, no. 2, pp. 1-14, 2018.

[10] F. A. Rahmawati, H. Tolle, and R. Rokhmawati, "Pengembangan Sistem Informasi Monitoring Dan Evaluasi Hasil Kegiatan Pengawas Berbasis Web (Studi Kasus: Dinas Pendidikan Kota Malang) Aulia," $J$. Pengemb. Teknol. Inf. dan Ilmu Komput., vol. 3, no. 3, pp. 2452-2458, 2019.

[11] G. F. Nama, A. Munif Hanafi, M. Bagus Nurfaif, and M. Tesar Sandikapura, "Dashboard Monitoring System Berbasis Web Sebagai Pemantau Layanan liteBIG Instant Messenger," J. Nas. Teknol. dan Sist. Inf., vol. 3, no. 1, pp. 19-26, 2017.

[12] Y. N. Kunang and S. D. Purnamasari, "Pengembangan dashboard monitoring stasiun cuaca berbasis web," 2017, no. April 2017.

[13] S. B. Hermanto and P. Patmawati, "Determinan Penggunaan Aktual Perangkat Lunak Akuntansi Pendekatan Technology Acceptance Model," J. Akunt. dan Keuang., vol. 19, no. 2, pp. 67-81, 2017.

[14] Sefrika and T. E. Alawiah, "Acceptance of Video Conference Technology as a Distance Learning Media with the TAM Method," Int. J. Inf. Syst. Technol., vol. 4, no. 36, pp. 465-470, 2020.

[15] W. Wiguna, "Adopsi Sistem Informasi Akademik Perguruan Tinggi," J. Inform., vol. 4, no. 2, pp. 189-197, 2017.

[16] A. P. Widodo, F. Agushybana, and S. P. Jati, "Pengukuran Penerimaan Sistem Informasi EWSKIA Berdasarkan Persepsi Pengguna dengan Menggunakan Technology Acceptance Model," J. Sist. Inf. Bisnis, vol. 8, no. 2, p. 166, 2018.

[17] BPS, Pedoman Teknis BPS Provinsi dan Kabupaten/Kota SP2020. Jakarta: BPS, 2019.

[18] F. D. Davis, "A technology acceptance model for empirically testing new end-user information systems: 
Theory and results," Management, vol. Ph.D., no. May, p. 291, 1985.

[19] Jogiyanto, Sistem Informasi Keperilakuan, Ed. 1. Yogyakarta: Andi Publisher, 2007.

[20] F. D. Davis, R. P. Bagozzi, and P. R. Warshaw, "User Acceptance of Computer Technology: A Comparison of Two Theoretical Models," Manage. Sci., vol. 35, no. 8, pp. 982-1003, 1989.

[21] V. Venkatesh and F. D. Davis, "Theoretical extension of the Technology Acceptance Model: Four longitudinal field studies," Manage. Sci., vol. 46, no. 2, pp. 186-204, 2000.

[22] V. Venkatesh, "Determinants of Perceived Ease of Use: Integrating Control, Intrinsic Motivation, and Emotion into the Technology Acceptance Model," Inf. Syst. Res., vol. 11 , no. 4, pp. 342-365, 2000.

[23] V. Venkatesh and H. Bala, "Technology acceptance model 3 and a research agenda on interventions," Decis. Sci., vol. 39, no. 2, pp. 273-315, 2008.

[24] F. D. Davis, R. P. Bagozzi, and P. R. Warshaw, "Extrinsic and Intrinsic Motivation to Use Computers in the Workplace," J. Appl. Soc. Psychol., vol. 22, no. 14, pp. 1111-1132, 1992.

[25] B. D. R. Compeau and C. A. Higgins, "Development of a Measure and Initial Test Background-Social," vol. 19, no. 2, pp. 189-211, 1995.

[26] F. D. Davis, "Perceived Usefulness , Perceived, And User Acceptance," MIS Q., vol. 13, no. 3, pp. 319-339, 1989.

[27] F. D. Davis and V. Venkatesh, "Toward preprototype user acceptance testing of new information systems: Implications for software project management," IEEE Trans. Eng. Manag., vol. 51, no. 1, pp. 31-46, 2004.

[28] P. R. Warshaw and F. D. Davis, "Disentangling behavioral intention and behavioral expectation," J. Exp. Soc. Psychol., vol. 21, no. 3, pp. 213-228, 1985.

[29] L. M. Maruping, H. Bala, V. Venkatesh, and S. A. Brown, "Going Beyond Intention: Integrating Behavioral Expectation Into the Unified Theory of Acceptance and Use of Technology," J. Assoc. Inf. Sci. Technol., pp. 1$15,2016$.

[30] V. Venkatesh, M. G. Morris, G. B. Davis, and F. D. Davis, "User Acceptance of Information Technology: Toward A Unified View," MIS Q., vol. 27, no. 3, pp. 425-478, 2003.

[31] F. D. Davis, "Perceived Usefulness, Perceived Ease Of Use, and User Acceptance of Information Technology," MIS Q., vol. 13, no. 3, pp. 319-340, 1989.

[32] I. G. N. M. Jaya and I. M. Sumertajaya, "Pemodelan Persamaan Structural dengan Partial Least Square," Semnas Mat. dan Pendidik. Mat. 2008, pp. 118-132, 2008.

[33] J. Sarwono and U. Narimawati, Membuat skripsi, tesis dan disertasi dengan Partial Least Square SEM (PLS SEM). Yogyakarta: Andi Publisher, 2015.
[34] Z. Hamidiana, C. Meidiana, and H. Suwasono, "Model Struktural Partial Least Square Karakteristik Masyarakat Terhadap Kuantitas dan Kualitas Mata Air (Studi Kasus Desa Gunungsari Kota Batu)," J-Pal, vol. 7, no. 2, pp. 104-111, 2016.

[35] Jogiyanto, Model Kesuksesan Sistem Teknologi Informasi, Ed. 1. Yogyakarta: Andi Publisher, 2007

[36] Hu Li-tze. and Peter M. Bentler, "Cutoff criteria for fit indexes in covariance structure analysis: Conventional criteria versus new alternatives," Struct. Equ. Model. A Multidiscip. J., vol. 6, no. 1, pp. 1-55, 1999.

[37] A. Z. Arsyika, E. Safrianti, and L. O. Sari, "Analisis Tingkat Penerimaan Pengguna Layanan Cloud Storage menggunakan Metode Technology Acceptance Model 3 (TAM3) pada Dinas Perpustakaan dan Arsip Kota Pekanbaru," Jom FTEKNIK, vol. 6, no. 2, pp. 1-11, 2019.

[38] Y. S. Wang, "The adoption of electronic tax filing systems: An empirical study," Gov. Inf. Q., vol. 20, no. 4, pp. 333-352, 2003.

[39] A. Al-Azawei, P. Parslow, and K. Lundqvist, "Investigating the effect of learning styles in a blended elearning system: An extension of the technology acceptance model (TAM)," Australas. J. Educ. Technol., vol. 33, no. 2, pp. 1-23, 2017.

[40] F. S. Rahayu, D. Budiyanto, and D. Palyama, "Analisis Penerimaan E-Learning Menggunakan Technology Acceptance Model (Tam) (Studi Kasus: Universitas Atma Jaya Yogyakarta)," J. Terap. Teknol. Inf., vol. 1, no. 2, pp. 87-98, 2017.

[41] P. J. Pesak, J. J. Sondakh, and H. Gamaliel, "FaktorFaktor yang Mempengaruhi Penggunaan Sistem E-audit Pada Badan Pemeriksa Keuangan Republik Indonesia Perwakilan Provinsi Sulawesi Utara," J. Ris. Akunt. Dan Audit. "Goodwill," vol. 10, no. 2, p. 170, 2019.

[42] P. Mauliana and S. Risnanto, "Pengukuran Sistem Informasi Akademik Universitas Sangga Buana YPKP Menggunakan Technology Acceptance Model," Infotronik J. Teknol. Inf. dan Elektron., vol. 4, no. 1, p. 33, 2019.

[43] S. Karouw, B. Narasiang, and J. Litouw, "Analisis Pengukuran Model Penerimaan Teknologi OpenSID di Area Rural dan Urban," Cogito Smart J., vol. 5, no. 2, pp. 191-202, 2019. 
